\title{
PHOSPHATE ESTERS IN MYOTONIC HUMAN MUSCLE
}

\author{
BY \\ P. C. CALDWELL* and T. A. J. PRANKERD \\ From the Departments of Biophysics and Neurology, University College and \\ University College Hospital, London
}

Myotonia congenita is a disorder of the relaxation of skeletal muscle in man. The disease is not accompanied by muscular wasting, and is analogous to a disorder in goats (Kolb, 1938 ; Brown and Harvey, 1939). The affected muscles both of man and goat show similar abnormalities when examined by histological and electromyographic methods. Myotonia becomes apparent during activity after a period of rest. Relaxation is delayed for up to a minute after the first voluntary contraction. With successive contractions the period of myotonic contraction decreases until the muscle eventually behaves like normal muscle.

Electromyographic investigations have suggested that both disorders are due primarily to an abnormally high excitability of the muscle membranes, but it is possible that other factors are operative. Current theories of muscular contraction (Baldwin, 1952) assign an important role to phosphate esters. The patient who is to be described willingly consented to biopsy of small samples of affected muscle to see if they showed abnormalities in the distribution of these esters and thus possibly throw further light on the nature of the disease.

\section{Case Report}

The patient was a man aged 42 years, in whom the symptoms of delayed muscular relaxation had been present since early childhood. There was no definite family history of a similar disorder. Myotonia was present regularly after rest, being most evident in the flexors of the fingers, the deltoids, and the quadriceps. A myotonic contraction also occurred on direct percussion of the muscles. This myotonia wore off after repeated contraction ; it was also diminished by quinine. There was no weakness or wasting; the facial muscles, and in particular the sternomastoids, were normally developed. No cataract could be detected on routine ophthalmoscopy.

Electromyography (Dr. W. D. Fletcher) showed the trains of oscillations characteristic of myotonia when the needle electrode was inserted and on mechanical stimulation of the muscles. After working off the

* I.C.I. research fellow. myotonia abnormal oscillations were no longer obtained. Estimations of daily urinary creatine and creatinine excretion were within normal limits.

\section{Results of Biopsies}

Two small samples of muscle, about $100 \mathrm{mg}$., were removed through an incision over the deltoids on each of two separate occasions. The samples were immediately fixed by immersion in a mixture of acetone and solid $\mathrm{CO}_{2}$ and then extracted with aqueous trichloracetic acid. The extract was analysed for phosphate esters by Caldwell's (1953) adaptation of the chromatographic method of Hanes and Isherwood (1949). The results are given in the Table. Sample 1 was taken from the left deltoid during rest and Sample 2 during a myotonic contraction of this muscle. Sample 3 was taken during a myotonic contraction of the right deltoid, and Sample 4 after the myotonia had been " worked off " by repeated movement of the arm. A sample of resting human muscle from a normal subject (Sample 5) was also examined, and the distribution of phosphate esters in this was very similar to those found by Nevin (1934).

The samples were found to contain, in addition to the usual ester fractions, some of the unidentified fractions which have recently been detected in tortoise muscle by the chromatographic method (Caldwell, 1953). Sample 4, in which the myotonia had been "worked off", was of particular interest, since, in addition to containing fractions which appeared to correspond to the unknowns $C$ and D found occasionally in tortoise muscles, it also contained an unidentified fraction, unknown $F$. The distances travelled by unknown $F$ in the two solvents used, were, in terms of that travelled by orthophosphate, 0.65 in n-propanol/ammonia and 0.8 in tertbutyl alcohol/picric acid.

The quantitative findings suggest that the distribution of esters in muscle samples showing symptoms of myotonia is like that in fatigued normal muscle, that is, the creatine phosphate concentration is low and the orthophosphate and monophos- 
TABLE

PHOSPHATE ESTER DISTRIBUTIONS EXPRESSED AS PERCENTAGE OF THE EXTRACTABLE P

\begin{tabular}{|c|c|c|c|c|c|}
\hline \multirow{3}{*}{ Ester } & \multicolumn{4}{|c|}{ Myotonic Muscle } & \multirow{2}{*}{$\begin{array}{c}\text { Normal } \\
\text { Muscle } \\
\end{array}$} \\
\hline & \multicolumn{3}{|c|}{$\begin{array}{c}\text { Showing Signs of } \\
\text { Myotonia }\end{array}$} & \multirow{2}{*}{$\begin{array}{c}\text { Not } \\
\text { Showing } \\
\text { Signs } \\
\text { of } \\
\text { Myo- } \\
\text { tonia } \\
\text { Sample } \\
4 \\
\text { after } \\
\text { Working } \\
\text { off } \\
\text { Myo- } \\
\text { tonia }\end{array}$} & \\
\hline & $\begin{array}{l}\text { Sample } \\
\quad \text { Resting }\end{array}$ & $\begin{array}{c}\underset{2}{\text { Sample }} \\
\text { during } \\
\text { Myo- } \\
\text { tonia }\end{array}$ & $\begin{array}{l}\underset{3}{\text { Sample }} \\
\text { during } \\
\text { Myo- } \\
\text { tonia }\end{array}$ & & $\begin{array}{l}\underset{5}{\text { Sample }} \\
\text { Resting }\end{array}$ \\
\hline $\begin{array}{l}\text { ATP and ADP } \\
\text { Creatine phosphate } \\
\text { Orthophosphate ... } \\
\text { Monophosphate }\end{array}$ & $\begin{array}{r}28 \cdot 2 \\
2 \cdot 3 \\
24 \cdot 7\end{array}$ & $\begin{array}{r}28 \cdot 6 \\
0.0 \\
25 \cdot 9\end{array}$ & $\begin{array}{l}30 \cdot 9 \\
16 \cdot 3 \\
27 \cdot 0\end{array}$ & $\begin{array}{l}27 \cdot 2 \\
21 \cdot 6 \\
25 \cdot 2\end{array}$ & $\begin{array}{l}34 \cdot 9 \\
40 \cdot 4 \\
17 \cdot 1\end{array}$ \\
\hline $\begin{array}{l}\text { Diphosphate esters } \\
\text { (the value for } \\
\text { sample } 4 \text { includes } \\
\text { unknown D) }\end{array}$ & $\begin{array}{l}27 \cdot 0 \\
12 \cdot 3\end{array}$ & $\begin{array}{l}35 \cdot 1 \\
10 \cdot 4\end{array}$ & $\begin{array}{l}5 \cdot 8 \\
6 \cdot 6\end{array}$ & $\begin{array}{l}0 \cdot 0 \\
2 \cdot 2\end{array}$ & $\begin{array}{l}0 \cdot 0 \\
2 \cdot 8\end{array}$ \\
\hline $\begin{array}{ll}\text { Unknown A } & \ldots \\
\text { Unknown B } & \ldots \\
\text { Unknown C } & \end{array}$ & $\overline{5 \cdot 6}$ & $\overline{0.0}$ & $\begin{array}{l}6 \cdot 2 \\
7 \cdot 3 \\
-\end{array}$ & $\begin{array}{r}5.4 \\
1.2 \\
11.7\end{array}$ & $\begin{array}{l}2.8 \\
1.9 \\
-\end{array}$ \\
\hline Unknown $F \quad \therefore$ & - & - & - & $6 \cdot 1$ & - \\
\hline $\begin{array}{l}\text { P not extracted by } \\
\text { trichloroacetic } \\
\text { acid }(\mu \mathrm{g} . \mathrm{P} / \mathrm{g}) \ldots\end{array}$ & 232 & 215 & 149 & 124 & 238 \\
\hline
\end{tabular}

phate esters are high. After the process of "working off" the myotonia, the amounts of creatine phosphate and the monophosphate esters become more like those in normal resting muscle and unidentified esters appear.

Intense electrical activity takes place along myotonic muscle on both nervous and mechanical stimulation, the resulting myotonic contraction being similar to that during tetanic stimulation of normal muscle (Brown and Harvey, 1939). Since all three samples of myotonic muscle would have been stimulated mechanically by the removal of the biopsy material in addition to any nerve stimulation, it is not surprising to find that the amounts of creatine phosphate and monophosphate esters are similar to those found in normal muscle fatigued by tetanic stimulation. After the process of "working off" the myotonic muscle resembles normal muscle in its electrical behaviour. It does not undergo a myotonic contraction on removal of the biopsy material and the amounts of creatine phosphate and monophosphate esters resemble those in normal muscle.

Since the changes in creatine phosphate and the monophosphate esters can be interpreted in terms of the behaviour of these compounds in normal muscle and the electrical properties of myotonic muscle, it is unlikely that they contribute directly to the myotonia. Thus, on this interpretation, myotonia remains entirely a result of the hyperexcitability of the muscle membrane. The significance of the unidentified compounds which appeared after "working off" and any connexion they may have with the condition is obscure.

We wish to thank Dr. E. A. Blake Pritchard for permission to make these observations on this case, and to Dr. A. J. Bowdler for assistance with the biopsies.

\section{REFERENCES}

Baldwin, E. (1952). Dynamic Aspects of Biochemistry. Univ. Press. Camb.

Brown, G. L., and Harvey, A. M. (1939). Brain, 62, 341.

Caldwell, P. C. (1953). J. Biochem., 55, 458.

Hanes, C. S., and Isherwood, F. A. (1949). Nature, Lond., 164, 1107 Kolb, L. C. (1938). Bull. Johns Hopk. Hosp., 63, 221. Nevin, S. (1934). Brain, 57, 239. 